\title{
A Rare Case of Coronary Cameral Fistula from Left Circumflex Artery Draining into the Left Ventricular Apex Presenting as Angina Pectoris: A Case Report
}

\author{
Manish Pendseㄹ, Nilesh Walke², Monika Jawanjal'1, Ghanashyam Kane ${ }^{1}$ \\ ${ }^{1}$ Padmashree Dr. D. Y. Patil Hospital, Nerul, Navi Mumbai, India \\ ${ }^{2}$ Apollo Hospital, Chennai, India \\ Email:drmanishpendse@gmail.com,drnilesh37@gmail.com,drmonika257@gmail.com
}

Received 23 May 2016; accepted 4 July 2016; published 7 July 2016

Copyright (@) 2016 by authors and Scientific Research Publishing Inc.

This work is licensed under the Creative Commons Attribution International License (CC BY).

http://creativecommons.org/licenses/by/4.0/

(c) $\underset{\mathrm{EY}}{\mathrm{EY}}$ Open Access

\begin{abstract}
Coronary cameral fistula (CCF) is a very rare coronary anomaly in which a communication exists between one of the coronaries and a cardiac chamber. Most of the times it is an incidental finding detected at the time of a coronary angiography. However, sometimes it can have serious presentation like unstable angina, coronary steal or ventricular arrhythmia. We present a rare case of coronary cameral fistula arising from left circumflex artery (LCx) draining in to left ventricular (LV) apex and presenting as unstable angina.
\end{abstract}

\section{Keywords}

Coronary Cameral Fistula (CCF), Coronary Angiography, Left Circumflex (LCx)

\section{Introduction}

Coronary cameral fistula (CCF) is an extremely rare coronary anomaly in which there is a communication between one of the coronary arteries and any of the cardiac chambers [1]. Coronary cameral fistula is generally congenital in origin but very rarely it can be acquired secondary to trauma or coronary catheterization [2] [3].

The clinical presentation generally depends on the location and the size of the fistula and the degree of compromise in blood supply [1] [3].

We present a case of a very late presentation of this congenital coronary anomaly, who presented to the Emergency Department (ED) for the first time at the age of 59 years with unstable angina. 


\section{Case Presentation}

A 59 years old male presented to the emergency department with complains of retrosternal chest pain which was new onset and associated with mild breathlessness at around 11 pm at night. There was no history of similar episode in the past. There was no history of hypertension, diabetes or any other major cardiac or non- cardiac illness in past.

On presentation his pulse was 86 per minute and blood pressure was 156/90 mm of Hg. The clinical examination did not reveal any significant abnormality. The Electrocardiogram (ECG) done in the emergency department revealed mild concentric left ventricular hypertrophy ( $\mathrm{LVH}$ ) and minimal ST segment depression in lateral leads. However, cardiac enzymes were mildly raised viz. Troponin T was $0.11 \mathrm{ng} \%$. So, the patient was admitted in intensive care unit and was treated on the lines of unstable angina. The other biochemical and hematological parameters were in normal range and they are as follows (see Table 1).

Transthoracic echocardiography was done in the intensive care unit which showed left ventricular hypertrophy and a small abnormal channel just at the left ventricular apex. However the channel could not be delineated completely in the transthoracic study. The patient improved symptomatically after treatment with oral nitrates.

The next day, coronary angiography (CAG) was performed. The angiography showed that there was an abnormal spillage of the contrast in the left ventricular cavity in the apical region in diastole. The further study confirmed the presence of a channel communicating between left circumflex artery and the left ventricle and the diagnosis of a coronary cameral fistula arising from left circumflex draining into left ventricular apex (see Figure 1) was confirmed. The arrows in both the figures that the left ventricular cavity was opacified with the contrast in diastole. There were no significant atherosclerotic plaques in any of the coronaries. Both the renal arteries were normal (Figure 2).

In our patient there was no acquired cause for the development of the fistula from left circumflex to left ventricular apex i.e. trauma or previous coronary catheterization. So the diagnosis of coronary cameral fistula from left circumflex artery to left ventricular (LV) apex of congenital origin was confirmed.

As there was no significant atherosclerotic coronary artery disease, the patient was advised medical management with calcium channel blockers, ACE inhibitors with aspirin and statin viz. atorvastatin. The patient was discharged after 3 days of hospitalization and followed up for three months so far. He is doing well with the medical management without any complains.

\section{Discussion}

Coronary cameral fistula is an exceedingly rare cardiac anomaly. It is a communication between any of the coronary artery with one of the cardiac chambers or a major vessel viz. venae cavae, pulmonary artery, veins, or coronary sinus or other coronary [1] [2]. Most of the coronary cameral fistulae are congenital in origin. However very rarely they are seen acquired after trauma or cardiac catheterization [2] [3]. Majority of the coronary cameral fistulae arise from right coronary artery (55\%), left coronary artery (35\%), and both coronary arteries (5\%) and they generally drain into the right ventricle (40\%), right atrium (26\%), pulmonary arteries (17\%) and less

\begin{tabular}{cc} 
Table 1. Hematological and biochemical parameters in our patient. \\
\hline Hemoglobin (Hb) & $14.4 \mathrm{gm} \%$ \\
Total Leucocyte Count (TLC) & $8900 / \mathrm{mm}^{3}$ \\
Red Blood Cell count (RBC) & $4.4 \mathrm{millions} / \mathrm{mm}^{3}$ \\
Platelet Count (PLT) & $231,000 / \mathrm{mm}^{3}$ \\
Hematocrit (HCT) & $41 \%$ \\
Serum Creatinine & $0.9 \mathrm{mg} / \mathrm{dl}$ \\
Blood urea Nitrogen (BUN) & $16 \mathrm{mg} \%$ \\
Total Cholesterol (TC) & $196 \mathrm{mg} / \mathrm{dl}$ \\
Triglycerides (TG) & $160 \mathrm{mg} / \mathrm{dl}$ \\
Low Density Lipoproteins (LDL) & $99 \mathrm{mg} / \mathrm{dl}$ \\
High Density Lipoproteins (HDL) & $46 \mathrm{mg} / \mathrm{dl}$ \\
Fasting Blood Sugar (FBS) & $98 \mathrm{mg} \%$ \\
\hline
\end{tabular}




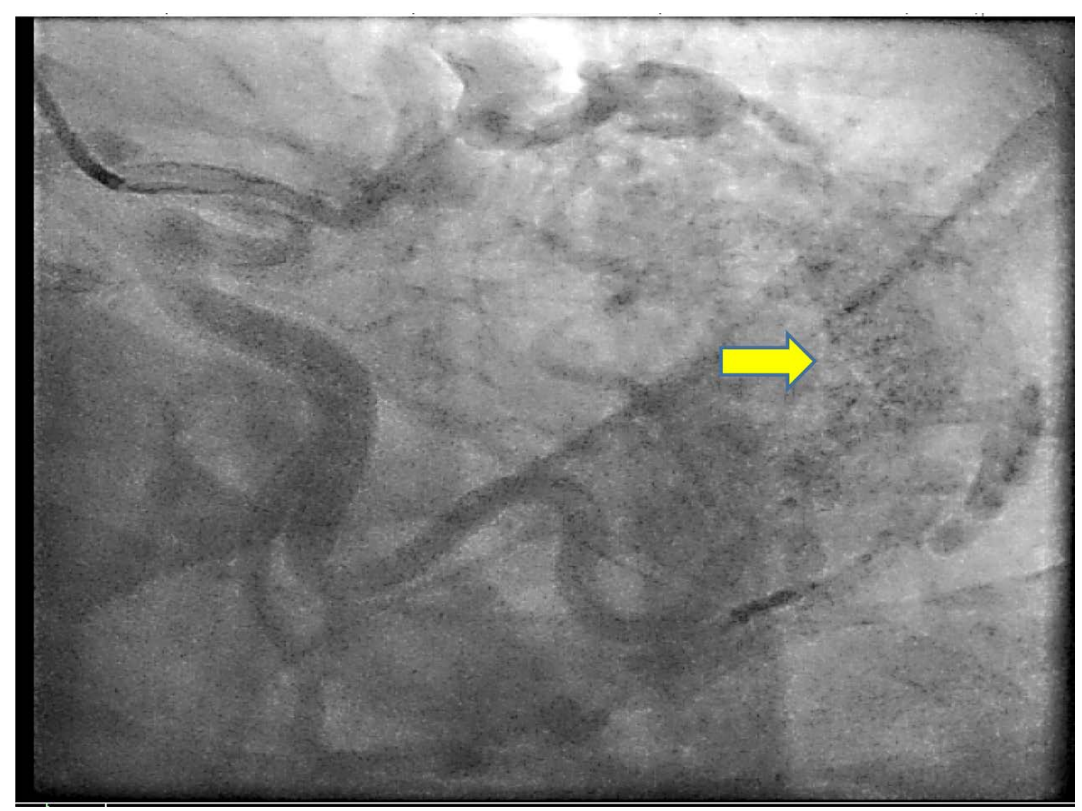

Figure 1. RAO caudal view, left ventricular cavity showing spillage of contrast (Arrow) from a fistula from left circumflex draining into left ventricular apex.

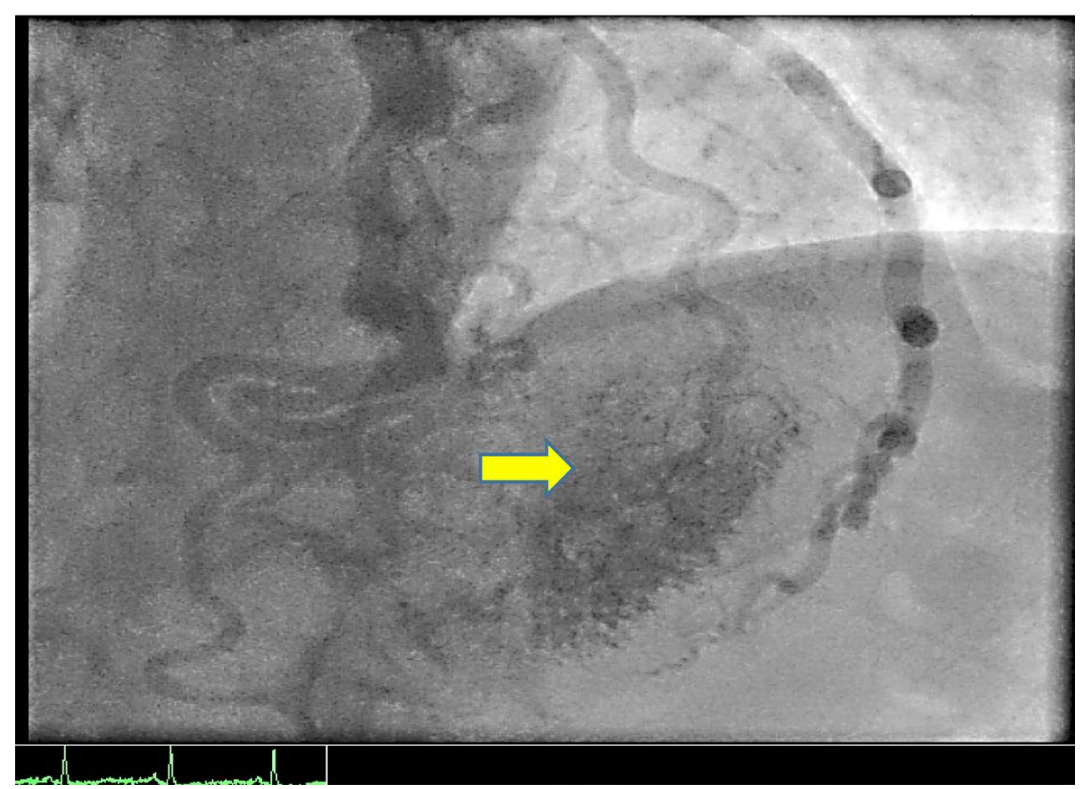

Figure 2. LAO cranial view showing contrast in the left ventricular cavity (Arrow) with tortuous fistula arising from left circumflex artery draining into LV apex.

frequently the superior vena cava or coronary sinus and least often the left atrium and left ventricle [2]-[4].

Coronary artery to left ventricular fistulae are very rare with the incidence being reported as $1.2 \%$ of all coronary artery fistulae [1] [4] [5]. As per Houser et al., a fistula arising from left circumflex artery draining into left ventricle is exceedingly rare and very few cases have been reported so far in the literature [1] [3].

The clinical presentation depends mainly on the location and the size of the fistula, the degree of compromise in blood supply and effective collaterals [1] [5] [6]. Generally, the hemodynamically significant fistula with a left to right shunt may lead to congestive heart failure, pulmonary arterial hypertension, myocardial ischemia, steal phenomenon or very rarely arrhythmias [1] [6] [7].

Cardiac catheterization with coronary angiography remains the gold standard for the diagnosis of coronary 
artery fistulae. It can demonstrate the size, anatomy, number, origin and the draining site of the fistulae. Transthoracic echocardiography is also useful in giving clue for the fistula [8]-[10]. Magnetic resonance imaging (MRI) can also help in delineating the fistulae and the diagnosis of this rare anomaly [9]. However conventional coronary angiography forms the mainstay in the diagnosis and decision making for the treatment of coronary cameral fistulae [1] [7] [10].

Most coronary artery fistulae are small and usually do not cause any ischemic symptoms and have good longterm prognosis [2]. Such asymptomatic fistulae with no abnormal flow pattern can be managed conservatively [1] [3].

In symptomatic cases, coils particularly controlled release coils can be used. In severe symptomatic cases where trans-catheter interventions are not possible, coronary artery bypass grafting (CABG) is an option [1] [9] [10].

\section{Conclusion}

Coronary cameral fistula is an extremely rare coronary anomaly. Particularly fistula arising from the left circumflex draining into Left ventricular cavity is exceedingly rare and very few cases have been reported in the literature. Our case was a very late presentation of this rare congenital coronary anomaly who presented for the first time at the age of 59 years with unstable angina. The early diagnosis of this rare anomaly determines the treatment and the outcome as hemodynamically significant coronary cameral fistula may lead to fatal complications like coronary steal, myocardial infarction or arrhythmias.

\section{References}

[1] Hauser, M. (2005) Congenital Anomalies of the Coronary Arteries. Heart, 91, 1240-1245. http://dx.doi.org/10.1136/hrt.2004.057299

[2] Said, S.A. and van der Werf, T. (1999) Acquired Coronary Cameral Fistulas: Are These Collaterals Losing Their Destination? Clinical Cardiology, 22, 297-302. http://dx.doi.org/10.1002/clc.4960220409

[3] Brooks, C.H. and Bates, P.D. (1983) Coronary Artery-Left Ventricular Fistula with Angina Pectoris. American Heart Journal, 106, 404-406. http://dx.doi.org/10.1016/0002-8703(83)90212-0

[4] Ho, H.H., Cheung, C.W., Jim, M.H. and Lam, L. (2005) Coronary Cameral Fistula. Heart, 91, 1540. http://dx.doi.org/10.1136/hrt.2005.064287

[5] Lessick, J., Kumar, G., Beyar, R., Lorber, A. and Engel, A. (2004) Anomalous Origin of a Posterior Descending Artery from the Right Pulmonary Artery: Report of a Rare Case Diagnosed by Multidetector Computed Tomography Angiography. Journal of Computer Assisted Tomography, 28, 857-859. http://dx.doi.org/10.1097/00004728-200411000-00023

[6] Lee, J., Choe, Y.H., Kim, H.J. and Park, J.E. (2003) Magnetic Resonance Imaging Demonstration of Anomalous Origin of the Right Coronary Artery from the Left Coronary Sinus Associated with Acute Myocardial Infarction. Journal of Computer Assisted Tomography, 27, 289-291. http://dx.doi.org/10.1097/00004728-200303000-00032

[7] Stierle, U., Giannitsis, E., Sheikhzadeh, A. and Potratz, J. (1998) Myocardial Ischemia in Generalized Coronary Artery-Left Ventricular Microfistulae. International Journal of Cardiology, 63, 47-52. http://dx.doi.org/10.1016/S0167-5273(97)00280-5

[8] Koh, K.K., Cho, S.K. and Kim, S.S. (1993) Left and Right Coronary Artery to Left Ventricular Fistula: Demonstration of Myocardial Ischemia by Treadmill Test and Holter Monitoring-A Case Report. Angiology, 44, 977-980. http://dx.doi.org/10.1177/000331979304401209

[9] Kiuchi, K., Nejima, J., Kikuchi, A., Takayama, M., Takano, T. and Hayakawa, H. (1999) Left Coronary Artery-Left Ventricular Fistula with Acute Myocardial Infarction, Representing the Coronary Steal Phenomenon: A Case Report. Journal of Cardiology, 34, 279-284.

[10] Qureshi, S.A. and Tynan, M. (2001) Catheter Closure of Coronary Artery Fistulas. Journal of Interventional Cardiology, 14, 299-307. http://dx.doi.org/10.1111/j.1540-8183.2001.tb00336.x 


\section{Abbreviations}

CCF = Coronary Cameral Fistula, LV = Left Ventricle, CAG = Coronary Angiography, LCx = Left Circumflex, $\mathrm{ED}=$ Emergency Department, ECG = Electrocardiogram, Hb = Hemoglobin, TLC = Total Leucocyte Count, RBC = Red Blood Cell count, PLT = Platelet Count, HCT = Hematocrit, BUN = Blood Urea Nitrogen, TC = Total Cholesterol, TG = Triglycerides, LDL = Low Density Lipoproteins, HDL = High Density Lipoproteins, FBS = Fasting Blood Sugar, LVH = Left Ventricular Hypertrophy, MRI = Magnetic Resonance Imaging

\section{Submit or recommend next manuscript to SCIRP and we will provide best service for you:}

Accepting pre-submission inquiries through Email, Facebook, Linkedin, Twitter, etc A wide selection of journals (inclusive of 9 subjects, more than 200 journals)

Providing a 24-hour high-quality service

User-friendly online submission system

Fair and swift peer-review system

Efficient typesetting and proofreading procedure

Display of the result of downloads and visits, as well as the number of cited articles

Maximum dissemination of your research work

Submit your manuscript at: http://papersubmission.scirp.org/ 